\title{
Knowledge and perceptions of diabetes in a semi-urban Omani
} population

\author{
Mohammed A Al Shafaee*1, Sulaiman Al-Shukaili' ${ }^{1}$, Syed Gauher A Rizvi ${ }^{1}$, \\ Yahya Al Farsi ${ }^{1}$, Mushtaq A Khan ${ }^{1}$, Shyam S Ganguly ${ }^{1}$, Mustafa Afifi ${ }^{2}$ and \\ Samir Al Adawi ${ }^{3}$
}

\begin{abstract}
Address: ${ }^{1}$ Department of Family Medicine and Public Health, College of Medicine and Health Sciences, Sultan Qaboos University, Oman, ${ }^{2}$ Department of Non-Communicable Diseases, Ministry of Health (HQ), Oman and ${ }^{3}$ Department of Behavioural Medicine, College of Medicine and Health Sciences, Sultan Qaboos University, Oman

Email: Mohammed A Al Shafaee* - shafaee4@omantel.net.om; Sulaiman Al-Shukaili - sshukaili@yahoo.com; Syed Gauher A Rizvi - rizvigauhar@hotmail.com; Yahya Al Farsi - ymfarsi@yahoo.com; Mushtaq A Khan - mavelyn@squ.edu.om;

Shyam S Ganguly - ganguly@squ.edu.om; Mustafa Afifi - afifidr@yahoo.co.uk; Samir Al Adawi - jimbo@omantel.net.om

* Corresponding author
\end{abstract}

Published: 22 July 2008

BMC Public Health 2008, 8:249 doi:10.1 186/147/-2458-8-249

This article is available from: http://www.biomedcentral.com/I47/-2458/8/249

(c) 2008 Al Shafaee et al; licensee BioMed Central Ltd.

This is an Open Access article distributed under the terms of the Creative Commons Attribution License (http://creativecommons.org/licenses/by/2.0), which permits unrestricted use, distribution, and reproduction in any medium, provided the original work is properly cited.

\begin{abstract}
Background: Diabetes mellitus is a major public health problem in the Sultanate of Oman. This study aimed to evaluate the knowledge and perception of diabetes in a sample of the Omani general population, and the associations between the elements of knowledge and perception, and sociodemographic factors.

Methods: The study was carried out in two semi-urban localities. A total of 563 adult residents were interviewed, using a questionnaire specifically designed for the present study. In addition to demographic information, the questionnaire contained questions on knowledge related to diabetes definition, symptoms, risk factors, complications and preventative measures, as well as risk perception for diabetes.

Results: Knowledge of diabetes was suboptimal. The percentages of correct responses to questions on diabetes definition, classical symptoms, and complications were $46.5 \%, 57.0 \%$, and $55.1 \%$, respectively. Only $29.5 \%, 20.8 \%$ and $16.9 \%$ identified obesity, physical inactivity and a positive family history, respectively, as risk factors for diabetes. A higher level of education, a higher household income, and the presence of a family history of diabetes were found to be positively associated with more knowledge.

Conclusion: This study demonstrated that there is lack of awareness of major risk factors for diabetes mellitus. Level of education is the most significant predictor of knowledge regarding risk factors, complications and the prevention of diabetes. Given that the prevalence of diabetes has increased drastically in Oman over the last decade, health promotion seems essential, along with other means to prevent and control this emerging health problem.
\end{abstract}




\section{Background}

Diabetes mellitus (DM) continues to be a major threat to global public health [1,2]. More than 170 million people worldwide have diabetes, and this figure is projected to more than double by the year 2030, if current trends continue [3]. The global increase in diabetes is triggered by, and associated with many factors, including the ageing population, and the unhealthy diets and sedentary lifestyles that heighten one's propensity towards obesity. In the industrialized countries of the West, diabetes is common among the elderly, in contrast with developing countries where diabetes most frequently affects those between the ages of 35 and 64 [4]. In some countries, DM also frequently occurs in youths [5].

The lack of an infrastructure for diabetic screening and high-risk group identification, in addition to inadequate public awareness and knowledge of diabetes symptoms may explain the failure of early diagnosis and, as a consequence, the burdens and loss of economic output associated with diabetes. There is growing evidence that preventing and/or delaying the onset of diabetes is a viable option [6,7]. Increased physical activity, modest weight reduction, and pharmacological interventions can decrease the incidence of diabetes complications significantly, even among high-risk groups. Simple lifestyle modifications, such as a healthy diet that includes reducing sugar intake, are considered to be essential for the prevention and control of incident diabetes mellitus [8-10]. Thus, increasing public awareness regarding modifiable diabetes risk factors and healthier lifestyles, and developing strategies to identify and manage at-risk populations, are among of the various possible mechanisms being used to stem the present epidemic of diabetes in many parts of the world.

The prevalence of diabetes in the Sultanate of Oman in 2000, as revealed by the 2000 National Health Survey, was $11.6 \%$, compared with $8.3 \%$ in 1991 , representing an increase of $40 \%$ over a single decade [11]. Additional increases in diabetes prevalence are likely, in light of projected changes in overall population growth, continuous adverse changes in dietary habits, and increasing numbers of people who are overweight, obese, or less physically active. Higher prevalence rates of diabetes have been identified in more urbanized areas of the country (18\%) relative to more rural areas (11\%) [12].

It is widely accepted that many problems, previously thought of as primarily medical and, hence, demanding conventional medical intervention, are in fact more appropriately disentangled by changing individual and social attitudes and behaviors [13]. Many health promotion strategies have had only modest success, because prevailing knowledge and perceptions often seem to override biomedical assumptions and considerations [14]. Various recent studies conducted in many parts of the world suggest that there is a lack of public awareness and knowledge of various factors related to diabetes [15-17]. This study aims to evaluate the level of knowledge and overall perceptions of diabetes within the general population of Oman. To the best of our knowledge, no such study has been conducted previously in the Sultanate of Oman.

\section{Methods \\ Study population}

This study was carried out in two semi-urban villages. As part of the Village Health Care Course, provided by the College of Medicine and Health Sciences at Sultan Qaboos University, two villages - Al Rumais and Al-Shuaiba, located $60 \mathrm{~km}$ and $80 \mathrm{~km}$ north of the University, respectively - were selected to carry out this field study. These two semi-urban villages are adjacent to the metropolitan city of Muscat, which also is the capital city of Oman. The demographics of these two villages are at least somewhat representative of the ethnicity and different strata of Omani society, by virtue of them being satellite towns of the capital, which has recently attracted migration from different parts of the country [12].

After receiving administrative approval from local authorities, as well as ethics approval from the College of Medicine \& Health Sciences, all households in the two villages were visited, whereupon information regarding the nature and general purpose of the study was provided. Those households in which informed consent to participate was granted were included in this study. Within each household, all persons 20 years of age or older were included in the sampling frame, which ultimately was comprised of 628 eligible persons. If any eligible household member was not available to complete the interview, arrangements were made for a follow-up interview. A maximum of three attempts were made to contact each eligible person during the survey period, which spanned from the $6^{\text {th }}$ to $14^{\text {th }}$ of January, 2007. A total of 563 eligible adults were interviewed, representing a response rate of $89.6 \%$. When there were multiple respondents from the same household, they were interviewed separately to avoid peer or family influence. Individuals who reported a history of diabetes mellitus among first-degree relatives were considered to have a positive family history.

\section{Measurement}

A review of the literature concerning different aspects of public knowledge and perceptions towards diabetes identified potential items to include in the survey questionnaire used in this study $[18,19]$. The final survey instrument contained 24 items, subdivided into 5 sections. The first two sections included questions on participant demographics and medical history. The third 
section was intended solely for diabetic participants and covered their diabetic history and glycemic control status. Knowledge regarding diabetes definition, risk factors, signs and symptoms, and complications was examined in the fourth section. The last section concentrated on the perceived risk of developing diabetes, as well as the participant's perception regarding diabetes prevalence, prevention and community awareness.

The questionnaire used Likert-type response scales. In order to collect additional data otherwise unobtainable with a typical Likert scale, open-ended questions were included, as well. For example, the closed-ended question - "Do you use your treatment regularly?" - was followed by the open-ended question - "If no, what are the reasons?"

The questionnaire was pre-tested and piloted within a convenience sample of students and staff at the College of Medicine and Health Sciences at Sultan Qaboos University. Its psychometric properties were found to be adequate. For consistency, and to accommodate illiterate subjects and those with sensory and motor deficits, the questionnaires were read out loud to the subjects, rather than being self-administered. The interviews were conducted by 15 trained researchers, predominantly 3rd and 4 th year medical students from the College of Medicine and Health Sciences at Sultan Qaboos University. During our preparation for this study, the interviewers were trained to read out the items of the questionnaire clearly and consistently, and to code the responses with precision and reliability; we observed substantial inter-coding agreement for the scale items $(\mathrm{r}=0.86, \mathrm{p}<0.001)$.

\section{Statistical analysis}

The association between study variables assessing (1) components of risk factor-related knowledge (e.g., excessive sugar intake, obesity, reduced physical activity, the presence of a family history); and (2) preventative measures (e.g., healthy dietary practises, increasing physical activity and avoiding obesity); and (3) certain sociodemographic characteristics (e.g., participant gender, age, educational status, monthly income and family history of diabetes) were determined by estimating the difference in proportions, using Pearson's chi-square analysis. The relationship between the various components of knowledge (i.e., disease definition, symptoms, risk factors, complications and preventive measures) and socio-demographic factors were evaluated separately using adjusted odds ratios with 95\% confidence intervals. To accomplish this, a binary logistic regression model utilizing the step-wise backward conditional method was created and tested for each component. For this, the knowledge of the individual was considered as the dependent variable and was coded " 1 " if the respondent was found to be aware and
"0" otherwise. Odds ratios were assessed for significance using Wald analysis. All significance tests were two-tailed, and a probability value of less than 0.05 was considered statistically significant. All data variables were processed, and analysis was performed using SPSS version 10 for Windows.

\section{Results}

A total of 563 individuals were surveyed. Demographic and clinical characteristics of the subjects and gender differences are shown in Table 1. It can be observed that $86.1 \%$ of the subjects were below the age of 50 years. About forty-six percent had studied up to high school or college levels. A positive family history of diabetes and personal diabetes were reported by $53.8 \%$ and $6.6 \%$ of the subjects, respectively. No statistically significant gender differences in demographic characteristics were identified $(\mathrm{p}>0.05)$ in terms of self-reported diabetes, hypertension, or family history of diabetes.

Three hundred and twenty subjects (56.8\%) reported that they were aware of the meaning of the condition called diabetes. However, when they were asked to define it, only 262 subjects (46.5\%) were able to give at least a rudimentary definition (data not shown in the table). Most frequently, diabetes is defined as 'a disease in which there are elevated levels of sugar in the blood'.

Three hundred and twenty one of the subjects (57.0\%) knew at least one of the classical symptoms of diabetes, like polyuria, polydipsia or unexplained weight loss. Polyuria was the most commonly identified symptom reported by 252 subjects (44.8\%) followed by unexplained weight loss $139(24.7 \%)$, polydipsia 113 $(20.1 \%)$, lethargy $64(11.4 \%)$ and giddiness $62(11.4 \%)$. A significant gender differential was noticed with respect to identifying unexplained weight loss, giddiness and malaise as symptoms of diabetes $(\mathrm{p}<0.05)$ (data not shown in the table).

Rates of awareness regarding important diabetes risk factors - like excessive sugar intake, obesity, physical inactivity and the presence of a family history - are shown in Table 2. About 59.9\% perceived high consumption of dietary sugar as an important risk factor for developing diabetes. Only $29.5 \%, 20.8 \%$ and $16.9 \%$ perceived obesity, physical inactivity and positive family history, respectively, as risk factors for diabetes. Awareness of physical inactivity as a risk factor was more common among male subjects. Younger subjects were more aware of the risk factors of diabetes. Recognizing the presence of a family history as a significant risk factor for developing diabetes was infrequent among subjects, but more common among the educated and those with higher incomes. Those who reported a positive family history of diabetes were not 
Table I: Demographic characteristics of the sample and gender differences

\begin{tabular}{|c|c|c|c|c|c|c|c|}
\hline & \multicolumn{2}{|c|}{ Males } & \multicolumn{2}{|c|}{ Females } & \multicolumn{2}{|c|}{ Total } & \multirow[t]{2}{*}{ p-value ${ }^{+}$} \\
\hline & $(n=237)$ & $42.1 \%$ & $(n=326)$ & $57.9 \%$ & $(n=563)$ & $100 \%$ & \\
\hline Age group & & & & & & & 0.023 \\
\hline $20-30$ yrs. & 128 & 54.0 & 170 & 52.2 & 298 & 52.9 & \\
\hline $31-50$ yrs. & 67 & 28.3 & 120 & 36.8 & 187 & 33.2 & \\
\hline$>50$ yrs. & 42 & 17.7 & 36 & 11.0 & 78 & 13.9 & \\
\hline Educational status & & & & & & & 0.030 \\
\hline Illiterate & 34 & 14.3 & 78 & 23.9 & 112 & 19.9 & \\
\hline Less than high school & 84 & 35.4 & 105 & 32.2 & 189 & 33.6 & \\
\hline High school & 72 & 30.4 & 95 & 29.2 & 167 & 29.6 & \\
\hline Some college or more & 47 & 19.8 & 48 & 14.7 & 95 & 16.9 & \\
\hline Monthly household income & & & & & & & 0.005 \\
\hline Less than 300 OMR*. & 72 & 31.3 & 139 & 44.7 & 211 & 39.0 & \\
\hline $300-1000$ OMR. & 126 & 54.8 & 143 & 46.0 & 269 & 49.7 & \\
\hline More than 1000 OMR. & 32 & 13.9 & 29 & 09.3 & 61 & 11.3 & \\
\hline Diabetes status- self reported & & & & & & & 0.567 \\
\hline Diabetic & 14 & 05.9 & 23 & 07.1 & 37 & 06.6 & \\
\hline Non-diabetic & 223 & 94.1 & 303 & 92.9 & 526 & 93.4 & \\
\hline Hypertension status- self reported & & & & & & & 0.135 \\
\hline Hypertensive & 21 & 08.9 & 42 & 12.9 & 63 & 11.2 & \\
\hline Non-hypertensive & 216 & 91.1 & 284 & 87.1 & 500 & 88.8 & \\
\hline Family history of diabetes & & & & & & & 0.196 \\
\hline Positive history & 120 & 50.6 & 183 & 56.1 & 303 & 53.8 & \\
\hline No OR not sure & 117 & 49.4 & 143 & 43.9 & 260 & 46.2 & \\
\hline
\end{tabular}

* OMR $=$ Omani Rial which is 2.6 to US Dollar

$+p$-values for comparisons between the gender difference

much more aware of family history as a risk factor for DM than those with no positive family history for the disease.

Awareness of diabetes as a serious condition with resultant intransigent complications was suboptimal. Only $55.1 \%$ of the sample knew that diabetes is a condition that, if uncontrolled, can produce lifelong complications affecting different organs of the body. Visual problems were identified as complications by $24.3 \%$ of the subjects, followed by heart disease (20.4\%), kidney disease $(17.9 \%)$, stroke $(9.4 \%)$ and delayed wound healing and complicated diabetic foot $(6.0 \%)$.

Knowledge among non-diabetic respondents of common preventive measures, relative to socio-demographic factors, is shown in Table 3.

It can be seen that $63.1 \%$ reported that diabetes can be prevented by modifying dietary habits, and $42.3 \%$ felt that diabetes can be prevented by increasing physical activity; however, only $17.9 \%$ felt that avoiding obesity and reducing weight play important roles in the preven- tion of diabetes. Approximately $78.9 \%$ of the study sample perceived diabetes as a preventable condition. Awareness of increasing physical activity as a preventative measure was greater among male subjects $(\mathrm{p}<0.005)$. Additionally, younger subjects and those with a higher level of education and higher monthly incomes were more aware of common preventative measures for diabetes.

Associated variables pertaining to knowledge about the definition of diabetes; its symptoms, risk factors, complications; and preventative measures are shown in Table 4.

Age, sex, education, income and family history were entered into a multivariate logistic regression model for each potential predictor of knowledge about DM. However, age and sex were eliminated by the step-wise regression procedure. Analysis revealed that those with a high school education or higher were 4.69 times more likely to know the definition of diabetes than those with a lower level of education (95\% CI $3.22-6.82 ; \mathrm{p}<0.001)$. Higher education level also was significantly associated with 
Table 2: Knowledge of diabetes risk factors by demographic factors and family history of diabetes among non-diabetic respondents

\begin{tabular}{|c|c|c|c|c|c|c|c|c|}
\hline & \multicolumn{2}{|c|}{ Excessive sugar intake } & \multicolumn{2}{|c|}{ Obesity } & \multicolumn{2}{|c|}{ Physical inactivity } & \multicolumn{2}{|c|}{ Presence of family history } \\
\hline & $\%$ & $p$ & $\%$ & $p$ & $\%$ & $p$ & $\%$ & $p$ \\
\hline \multicolumn{9}{|l|}{ Gender } \\
\hline Males & 59.5 & 0.881 & 29.5 & 0.982 & 27.4 & 0.001 & 19.0 & 0.254 \\
\hline Females & 60.1 & & 29.4 & & 16.0 & & 15.3 & \\
\hline \multicolumn{9}{|l|}{ Age group } \\
\hline $20-30$ & 64.4 & 0.007 & 35.6 & 0.001 & 22.5 & 0.021 & 23.2 & 0.001 \\
\hline $31-50$ & 58.8 & & 25.7 & & 23.0 & & 11.8 & \\
\hline$>50$ & 44.9 & & 15.4 & & 9.0 & & 5.1 & \\
\hline \multicolumn{9}{|l|}{ Educational status } \\
\hline Illiterate & 50.0 & 0.0001 & 18.8 & 0.0001 & 12.5 & 0.0001 & 6.3 & 0.0001 \\
\hline$<$ high school & 50.8 & & 24.9 & & 16.9 & & 9.0 & \\
\hline High school & 69.5 & & 31.7 & & 19.8 & & 18.6 & \\
\hline$\geq$ Some college & 72.6 & & 47.4 & & 40.0 & & 42.1 & \\
\hline \multicolumn{9}{|c|}{ Monthly H. Hold Income } \\
\hline $\mathrm{OMR}<300$ & 54.0 & 0.038 & 26.5 & 0.009 & 15.6 & 0.0001 & 13.7 & 0.015 \\
\hline $300-1000$ & 63.6 & & 27.5 & & 20.8 & & 16.7 & \\
\hline$>1000$ & 68.9 & & 45.9 & & 41.0 & & 39.5 & \\
\hline \multicolumn{9}{|c|}{ Family History of Diabetes } \\
\hline Positive History & 63.4 & 0.067 & 30.0 & .758 & 21.8 & 0.528 & 19.5 & 0.076 \\
\hline No/Not sure & 55.8 & & 28.8 & & 19.6 & & 13.8 & \\
\hline Total/combined & $59.9 \%$ & & $29.5 \%$ & & $20.8 \%$ & & $16.9 \%$ & \\
\hline
\end{tabular}

$\mathrm{P}$-values for comparisons of knowledge between the groups for each risk factor

greater knowledge regarding diabetes symptoms (OR $3.27 ; 95 \%$ CI 2.22-4.82, p < 0.001)), risk factors (OR 3.66; 95\% CI 2.37-5.65; p < 0.001), complications (OR 1.93; 95\% CI 1.36-2.74; $\mathrm{p}<0.001$ ) and prevention (OR $3.44 ; 95 \%$ CI 2.19-5.41; p < 0.001). Positive family history of diabetes also predicted each of these response variables. However, subject income level only was significantly associated with knowledge regarding diabetes definition and prevention.

\section{Discussion}

Oman has been successful in reducing the incidence of communicable diseases and increasing the standard of life among its people. Rapid cultural changes and social advances since 1970 have led to the manifestation of a wide range of non-communicable diseases. High prevalence rates for diabetes $(11.6 \%)$, obesity $(20.5 \%)$ and metabolic syndrome $(21.0 \%)$ exist in the Omani population [20]. It is recognized that health promotion, based upon societal knowledge and perceptions regarding chronic diseases like diabetes, is an essential component of any strategy aimed at disease control and prevention.
In order to lay the groundwork for health education for emerging health problems, in this study, we surveyed a semi-urban population of Oman regarding its level of knowledge and overall perceptions of diabetes. The data are somewhat discouraging. More than half of the subjects $(53.5 \%)$ were unable to provide even a rudimentary definition of diabetes, though they might be aware of its existence or have some idea about its symptoms or risk factors. Also, the study showed that knowledge regarding classic symptoms of diabetes was limited, and that two thirds of the subjects were unable to recognize obesity as a risk factor. Our results are not unlike those that have been reported elsewhere. Based upon the results of a survey they conducted in a metropolitan city in India, Mohan et al. reported that about one third of the general public was unaware of the term 'diabetes' [21]. The failure to define diabetes and to recognize its symptoms may reflect the general public's significant lack of knowledge about diabetes. This is likely to have negative repercussions, in terms of trying to control and prevent diabetes.

It is widely acknowledged that excessive sugar intake is a risk factor for incident diabetes mellitus [22]. Recent affluence in Oman has been marked by notable changes in die- 
Table 3: knowledge of common preventive measures by demographic factors and family history of diabetes among non-diabetic respondents

\begin{tabular}{|c|c|c|c|c|c|c|}
\hline & \multicolumn{2}{|c|}{ Taking Care of the Diet } & \multicolumn{2}{|c|}{ Increasing Physical Activity } & \multicolumn{2}{|c|}{ Avoiding Obesity \& overweight } \\
\hline & $\%$ & $\mathbf{p}$ & $\%$ & $p$ & $\%$ & $p$ \\
\hline \multicolumn{7}{|l|}{ Gender } \\
\hline Males & 61.2 & 0.432 & 49.8 & 0.002 & 19.0 & 0.581 \\
\hline Females & 64.4 & & 36.8 & & 17.2 & \\
\hline \multicolumn{7}{|l|}{ Age group } \\
\hline $20-30$ & 67.4 & 0.0001 & 53.4 & 0.0001 & 23.2 & 0.001 \\
\hline $31-50$ & 67.4 & & 36.4 & & 13.9 & \\
\hline$>50$ & 35.9 & & 14.1 & & 7.7 & \\
\hline \multicolumn{7}{|l|}{ Educational status } \\
\hline Illiterate & 38.4 & 0.0001 & 11.6 & 0.0001 & 8.9 & 0.004 \\
\hline$<$ high school & 61.4 & & 33.9 & & 15.3 & \\
\hline High school & 74.3 & & 56.3 & & 24.6 & \\
\hline$\geq$ Some college & 75.8 & & 70.5 & & 22.1 & \\
\hline \multicolumn{7}{|c|}{ Monthly H. Hold Income } \\
\hline OMR $<300$ & 57.3 & 0.034 & 30.3 & 0.0001 & 14.2 & 0.087 \\
\hline $300-1000$ & 66.9 & & 47.2 & & 18.2 & \\
\hline$>1000$ & 72.1 & & 62.3 & & 26.2 & \\
\hline \multicolumn{7}{|c|}{ Family History of Diabetes } \\
\hline Positive History & 66.8 & 0.117 & 46.2 & 0.042 & 19.5 & 0.306 \\
\hline No/Not sure & 59.6 & & 37.7 & & 16.2 & \\
\hline Total/combined & $63.1 \%$ & & $42.3 \%$ & & $17.9 \%$ & \\
\hline
\end{tabular}

$\mathrm{p}$-values for comparisons of knowledge between the groups for each of the preventive measures

Table 4: Predictors of knowledge of diabetes definition, symptoms, risk factors, complications and preventive measures based on fitting Stepwise multiple logistic regression models in the study groups

\begin{tabular}{|c|c|c|c|c|c|}
\hline & Definition & Symptoms & Risk factors & Complications & Prevention \\
\hline Demographic factor & OR $(95 \% \mathrm{Cl}) \mathrm{P}$ & OR $(95 \% \mathrm{Cl}) \mathrm{P}$ & OR $(95 \% \mathrm{Cl}) \mathrm{P}$ & OR $(95 \% \mathrm{Cl}) \mathrm{P}$ & OR $(95 \% \mathrm{Cl}) \mathrm{P}$ \\
\hline \multicolumn{6}{|l|}{ Education; } \\
\hline Less than high-school & 1.00 & & & & \\
\hline High-school \& above & $\begin{array}{c}4.69(3.22-6.82) \\
0.0001\end{array}$ & $\begin{array}{c}3.27(2.22-4.82) \\
0.0001\end{array}$ & $\begin{array}{c}3.66(2.37-5.65) \\
0.000 \mathrm{I}\end{array}$ & $\begin{array}{c}1.93(1.36-2.74) \\
0.0001\end{array}$ & $\begin{array}{c}3.44(2.19-5.4 \mathrm{I}) \\
0.000 \mathrm{I}\end{array}$ \\
\hline \multicolumn{6}{|l|}{$\begin{array}{l}\text { Family history of } \\
\text { DM; }\end{array}$} \\
\hline Yes & $\begin{array}{c}1.49(1.03-2.16) \\
0.034\end{array}$ & $\begin{array}{c}1.98(1.36-2.88) \\
0.0001\end{array}$ & $\begin{array}{c}\text { I.5I }(1.01-2.26) \\
0.044\end{array}$ & $\begin{array}{c}2.10(1.48-2.97) \\
0.0001\end{array}$ & $\begin{array}{c}1.58(1.05-2.37) \\
0.029\end{array}$ \\
\hline \multicolumn{6}{|l|}{ Income } \\
\hline $\begin{array}{l}<300 \text { OMR p.m. } \\
\geq 300 \text { OMR p.m. }\end{array}$ & $\begin{array}{c}1.00 \\
1.48(1.01-2.18) \\
0.047\end{array}$ & --------- & ------- & ------- & $\begin{array}{c}1.61(1.07-2.44) \\
0.024\end{array}$ \\
\hline
\end{tabular}

OR: Odds ratio; Cl: Confidence interval; DM: Diabetes mellitus. 
tary habits, which have included an increased likelihood of excessive sugar intake. Approximately $60 \%$ of the population surveyed perceived high consumption of dietary sugar as an important risk factor for developing diabetes. However, psychosocial studies consistently have shown that there is discrepancy between one's attitudes and behaviors [23]. Therefore, it remains to be seen whether knowledge regarding the adverse effects of excessive sugar intake will translate into personal decisions to curtail excessive sugar intake among Omanis.

The present study indicates that one's level of education has a direct influence on one's level of knowledge regarding the definition, symptoms, risk factors and complications of, and preventative measures against diabetes. This suggests that knowledge about diabetes is conducive to health education. This finding is congruent with other studies [24,25] albeit with a few exceptions [26]. In addition to education, a family history of diabetes also appears to influence one's level of knowledge and perceptions of diabetes. Individuals with a positive family history of a disease may develop a personal sense of vulnerability which, in turn, may increase their awareness, as was revealed in the present study [27]. Risk perception is an essential concept in a number of theoretical models addressing health-protective behaviors. Perceived risk is considered to be the primary motive to change within the Health Belief Model, which assumes that, the higher the perceived threat, the more likely an individual will modify his or her behavior to circumvent that threat $[28,29]$. A positive family history of a disease, and one's gender, age and perceptions of disease seriousness may affect one's level of perceived risk [30]. In support of this view, Harwell et al found that family history is the factor most significantly associated with the perceived risk of developing diabetes [31]. However, Pierce et al, in their randomized controlled trial, found that the family members of individuals with type 2 diabetes underestimate their own risk of developing the disease [32]. Factors influencing perceptions of family history may vary between individuals and between diseases. In the available literature and present findings, it has emerged that perceived risk may be important to motivate preventative health behaviors and control of disease [33].

One implication of the present findings is that, despite limited knowledge of diabetes, education that could be gleaned could play a critical role in coming to grips with the emerging epidemic of diabetes. More research is needed to identify how to increase public knowledge and perceptions of this disease.

\section{Limitations of the study}

Some limitations of this study should be highlighted. First, the findings of this study cannot be generalized to all of Oman, as the data were derived from semi-urban satellite towns adjacent to the capital of Muscat. However, the present findings lay the groundwork for further similar studies in other parts of the country. Second, to accommodate individuals who might be illiterate, the items were read to the subjects, rather than allowing them to selfadminister the questionnaire. It is possible that this approach might have resulted in subject reluctance to reveal sensitive feelings that may have been more fully elicited in a self-administered questionnaire. Having said this, the questionnaire was specifically devised not to pry into people's private lives; consequently, there is no explicit reason to suspect that subjects would be reluctant to respond honestly. Moreover, one confounding variable on this approach is the likelihood of lack of consistency in reading out the questions to the subjects bearing in mind that there were several different researchers dispending the questionnaire. Although this confounding factor remains, during the preparation of the study there was an acceptable inter-coding agreement. There also tends to be culturally-specific responses to questionnaires [34], a potential bias that was not explored in the present study, and which might have played a role, given that the study relied almost exclusively on self-reported, subjective data. These limitations and countless others that were not apparent, but are yet common in psychosocial studies, suggest that extrapolating the present findings to other populations should be viewed with caution.

\section{Conclusion}

The central objectives in this research were (1) to assess general population knowledge and perceptions of diabetes, and (2) to tease out whatever relationships that exist between the various components of knowledge and sociodemographic background in a semi-urban community in Oman. This study has demonstrated that significant numbers of Omanis lack the knowledge and perceptions required to prevent and cope with the increasing prevalence of diabetes in Oman. On the bright side, the study strongly implicates level of education as the most significant predictor of desirable knowledge and perceptions of diabetes risk factors, complications and prevention. This raises optimism that health education could be a powerful tool as we strive to develop strategies to fight debilitating and rapidly growing public health problems in Oman, problems that often are amenable to life style changes and, by implication, education.

\section{Competing interests}

The authors declare that they have no competing interests.

\section{Authors' contributions}

MAAS conceived and designed the study, analysed the data and drafted and finalized the manuscript. SAS participated in the design of the study, data analysis and the 
interpretation of results. SGAR participated in data analysis. YAF participated in the design of the study. MAK participated in statistical analysis and in manuscript revision. SSG and MA participated by scrutinizing the statistics in the tables and the results, and by providing assistance to address reviewers' comments. SAA participated by rewriting draft versions and critically revising the manuscript. All authors read and approved the final manuscript.

\section{Acknowledgements}

The authors would like to thank the individuals who participated in this survey, and the medical students at Sultan Qaboos University who interviewed the respondents and helped the study to take place. In addition, the authors would like to thank Dr. Azza Al-Abri for her generous assistance in the editing and electronic treatment of the data.

\section{References}

I. Abegunde DO, Mathers CD, Adam T, Ortegon M, Strong K: The burden and costs of chronic diseases in low-income and middle-income countries. Lancet 2007, 370:1929-1938.

2. Hjelm K, Mufunda E, Nambozi G, Kemp J: Preparing nurses to face the pandemic of diabetes mellitus: a literature review. J Adv Nurs 2003, $41: 424-434$.

3. Wild S, Roglic G, Green A, Sicree R, King H: Global prevalence of diabetes: estimates for the year 2000 and projections for 2030. Diabetes Care 2004, 27:1047-1053.

4. Diabetes Action Now: An Initiative of the World Health Organization and the International Diabetes Federation. WHO library cataloguing-in-publication data. Geneva, WHO; 2004.

5. Rosenbloom A, Joe J, Young R, Winter W: Emerging epidemic of type 2 diabetes in youth. Diabetes Care 1999, 22:345-354.

6. Chiasson JL: Prevention of Type 2 diabetes: fact or fiction? Expert Opin Pharmacother 2007, 8:3147-358.

7. Zinman B, Harris SB, Gerstein HC, Young TK, Raboud JM, Neuman J, Hanley AJ: Preventing type 2 diabetes using combination therapy: design and methods of the Canadian Normoglycaemia Outcomes Evaluation (CANOE) trial. Diabetes Obes Metab 2006, 8:53I-537.

8. Tuomilehto J, Lindström J, Eriksson JG, Valle TT, Hämäläinen $H$, llanne-Parikka $P$, Keinänen-Kiukaanniemi S, Laakso $M$, Louheranta $A$ Rastas M, Salminen V, Uusitupa M: Prevention of type 2 diabetes mellitus by changes in lifestyle among subjects with impaired glucose tolerance. N Engl J Med 200I, 344:1343-I350.

9. Knowler WC, Barrett-Connor E, Fowler SE, Hamman RF, Lachin JM, Walker EA, Nathan DM: Reduction in the incidence of type 2 diabetes with lifestyle intervention or metformin. $N$ Engl J Med 2002, 346:393-403.

10. American Diabetes Association and National Institute of Diabetes, Digestive and Kidney Diseases: The prevention or delay of type 2 diabetes. Diabetes Care 2002, 25:742-749.

II. Diabetes Mellitus Management Guidelines for primary health care 2nd edition. Oman: Ministry of Health; 2003.

12. Al-Moosa S, Allin S, Jemiai N, Al-Lawati j, Mossialos E: Diabetes and urbanization in the Omani population: an analysis of National survey data. Popul Health Metr 2006, 4:5-I2.

13. Al-Adawi S: Emergence of Diseases of Affluence in Oman: Where do they Feature in the Health Research Agenda? Sultan Qaboos University Medical Journal 2006, 6:3-9.

14. Hjelm K, Bard K, Nyberg P, Apelqvist J: Religious and cultural distance in beliefs about health and illness in women with diabetes mellitus of different origin living in Sweden. Int J Nurs Stud 2003, 40:627-643.

15. Gunay T, Ulusel B, Velipasaoglu S, Unal B, Ucku R, Ozgener N: Factors affecting adult knowledge of diabetes in Narlidere Health District, Turkey. Acta Diabetol 2006, 43: | 42-I47.

16. Angeles-Llerenas A, Carbajal-Sánchez N, Allen B, Zamora-Muñoz S, Lazcano-Ponce E: Gender, body mass index and socio-demographic variables associated with knowledge about type 2 diabetes mellitus among 13,293 Mexican students. Acta Diabetol 2005, 42:36-45.
17. Murugesan N, Snehalatha C, Shobhana R, Roglic G, Ramachandran A: Awareness about diabetes and its complications in the general and diabetic population in a city in southern India. Diabetes Res Clin Pract 2007, 77:433-437.

18. Kemple AM, Zlot Al, Leman RF: Perceived likelihood of developing diabetes among high-risk Oregonians. Prev Chronic Dis 2005, 2 Spec no:A07.

19. Tessaro I, Smith SL, Rye S: Knowledge and perceptions of diabetes in an Appalachian population. Prev Chronic Dis 2005, 2(2):AI3.

20. Al-Lawati JA, Mohammed AJ, Al-Hinai HQ, Jousilahti P: Prevalence of metabolic syndrome among Omani adults. Diabetes Care 2003, 26: I78|-|785.

21. Mohan D, Raj D, Shanthirani CS, Datta M, Unwin NC, Kapur A, Mohan V: Awareness and knowledge of diabetes in Chennai-the Chennai Urban Rural Epidemiology Study [CURES9]. J Assoc Physicians India 2005, 53:283-287.

22. Johnson RJ, Segal MS, Sautin Y, Nakagawa T, Feig DI, Kang DH, Gersch MS, Benner S, Sánchez-Lozada LG: Potential role of sugar (fructose) in the epidemic of hypertension, obesity and the metabolic syndrome, diabetes, kidney disease, and cardiovascular disease. Am J Clin Nutr 2007, 86:899-906.

23. Hjelm K, Bard K, Nyberg $P$, Apelqvist J: Management of gestational diabetes from the patient's perspective-a comparison of Swedish and Middle-Eastern born women. J Clin Nurs 2007, 16:168-78.

24. Hawthorne K, Tomlinson S: Pakistani Muslims with type 2 diabetes mellitus: effect of sex, literacy skills, known diabetic complications and place of care on diabetic knowledge, reported self-monitoring management and glycaemic control. Diabet Med 1999, 16:591-597.

25. Hawthorne K: Effect of culturally appropriate health education on glycaemic control and knowledge of diabetes in British Pakistani women with type 2 diabetes mellitus. Health Educ Res 2001, 16:373-381

26. Mehrotra R, Bajaj S, Kumar D, Singh KJ: Influence of education and occupation on knowledge about diabetes contro. Nat Med J India 2000, I 3:293-296.

27. Walter FM, Emery J, Braithwaite D, Marteau TM: Lay understanding of familial risk of common chronic diseases: a systematic review and synthesis of qualitative research. Ann Fam Med 2004, 2:583-594.

28. De Barr KA: A review of current health education theories. Californian J Health Promot 2004, 2:74-87.

29. Baranowski T, Cullen KW, Nicklas T, Thompson D, Baranowski J: Are current health behavioral change models helpful in guiding prevention of weight gain efforts? Obes Res 2003, I I(Suppl I):23S-43S.

30. Harrison TA, Hindorff LA, Kim H, Wines RC, Bowen DJ, McGrath $\mathrm{BB}, \mathrm{Edwards} \mathrm{KL}$ : Family history of diabetes as a potential public health too. Am J Prep Med 2003, 24: I52-I59.

31. Harwell TS, Dettori N, Flook BN, Priest L, Williamson DF, Helgerson SD, Gohdes D: Preventing type 2 diabetes: perceptions about risk and prevention in a population-based sample of adults $\geq$ 45 years of age. Diabetes Care 200I, 24:2007-2008.

32. Pierce $M$, Ridout $D$, Harding $D$, Keen H, Bradley $C$ : More good than harm: A randomized controlled trial of the effect of education about familial risk of diabetes on psychological outcomes. Br J Gen Pract 2000, 50:867-87I.

33. Walter FM, Emery J: Perceptions of family history across common diseases: a qualitative study in primary care. Fam Pract 2006, 23:472-480.

34. Wilks R, Younger N, Mullings J, Zohoori N, Figueroa P, Tulloch-Reid M, Ferguson T, Walters C, Bennett F, Forrester T, Ward E, Ashley D: Factors affecting study efficiency and item non-response in health surveys in developing countries: the Jamaica national healthy lifestyle survey. BMC Med Res Methodol 2007, 28(7): I 3 .

\section{Pre-publication history}

The pre-publication history for this paper can be accessed here:

http://www.biomedcentral.com/1471-2458/8/249/pre pub 